\title{
ANDES

www.scielo.cl

\section{Concurrencia de encefalitis diseminada aguda en lactante con Síndrome inflamatorio multisistémico asociado a infección por SARS-CoV-2}

\section{Concurrence of acute disseminated encephalitis in an infant with Multisystemic Inflammatory Syndrome associated with SARS-CoV-2 infection}

\author{
Camila Ampuero Acuñaa ${ }^{\mathrm{a}}$, Franco Díaz Rubio ${ }^{\mathrm{a}, \mathrm{b}}$, Alejandro Donoso Fuentes ${ }^{\mathrm{a}}$
}

aUnidad de Paciente Crítico Pediátrico, Hospital Clínico Dra. Eloísa Díaz I. La Florida. Santiago, Chile

${ }^{\mathrm{b} E s c u e l a ~ d e ~ M e d i c i n a, ~ U n i v e r s i d a d ~ F i n i s ~ T e r r a e . ~ S a n t i a g o, ~ C h i l e ~}$

\section{Sr. Editor,}

Entre el 6\% y el 58\% de los niños y adolescentes hospitalizados con Sindrome inflamatorio multisistémico (multisystem inflammatory syndrome, MIS-C) desarrollan compromiso neurológico, ya sea este predominantemente central o periférico ${ }^{1}$. Recientemente se ha publicado una relevante casuística nacional ${ }^{2}$ sobre las complicaciones neurológicas en los pacientes pediátricos con COVID-19, no obstante, es infrecuente el encontrar concurrencia de MIS-C y síntomas neurológicos graves originados por una encefalomielitis diseminada aguda (ADEM, del inglés Acute Disseminated Encephalomyelitis). La mayoría de los reportes que asocian COVID-19 y ADEM señalan el antecedente de infección previa unas pocas semanas antes por virus SARS-CoV-2 ${ }^{3}$.

Reconociendo la permanente actualización del aún limitado conocimiento respecto a las manifestaciones neurológicas graves de la infección por virus SARSCoV-2 en pediatría y con el objetivo de enriquecer la casuística nacional, nos parece importante comunicar la coexistencia de ADEM en un lactante con MIS-C.
Paciente de sexo femenino de 10 meses de edad, previamente sana, fue traída al servicio de urgencia por siete días de fiebre, irritabilidad, dolor abdominal, vómitos y diarrea. Su padre tuvo COVID-19 (SARSCoV-2 positivo en PCR de aspirado nasofaríngeo) un mes previo a la consulta. Dentro de los exámenes destacó leucocitosis de $20,5 \times 10^{3} / \mathrm{mm}^{3}$, trombocitopenia $45 \times 10^{3} / \mathrm{mm}^{3}$, elevación de marcadores inflamatorios, de daño miocárdico y dímero D mayor de $2000 \mathrm{ng} / \mathrm{mL}$ (VN: $<550 \mathrm{ng} / \mathrm{mL}$ ); ecocardiografía con derrame pericárdico leve; PCR de aspirado nasofaríngeo positiva para SARS-CoV-2 y serología con IgG positiva e IgM negativa. Se diagnosticó MIS-C (fenotipo No Kawasaki) asociado a disfunción hemodinámica grave, requiriendo ventilación mecánica invasiva y drogas vasoactivas (norepinefrina $0,3 \mathrm{ug} / \mathrm{kg} / \mathrm{min}$ y epinefrina $0,1 \mathrm{ug} /$ $\mathrm{kg} / \mathrm{min})$. Se administró inmunoglobulina endovenosa humana (IGIV) $(2 \mathrm{~g} / \mathrm{kg})$ y metilprednisolona endovenosa $(10 \mathrm{mg} / \mathrm{kg})$ por 3 días seguido de prednisona. Evolucionó favorablemente, afebril a las $24 \mathrm{~h}$ y extubándose a los 4 días. Posteriormente se evidenció importante hipotonía de predominio periférico, reflejos osteotendíneos disminuidos simétricos y compromiso

Correspondencia:

Alejandro Donoso Fuentes

adonosofuentes@gmail.com 


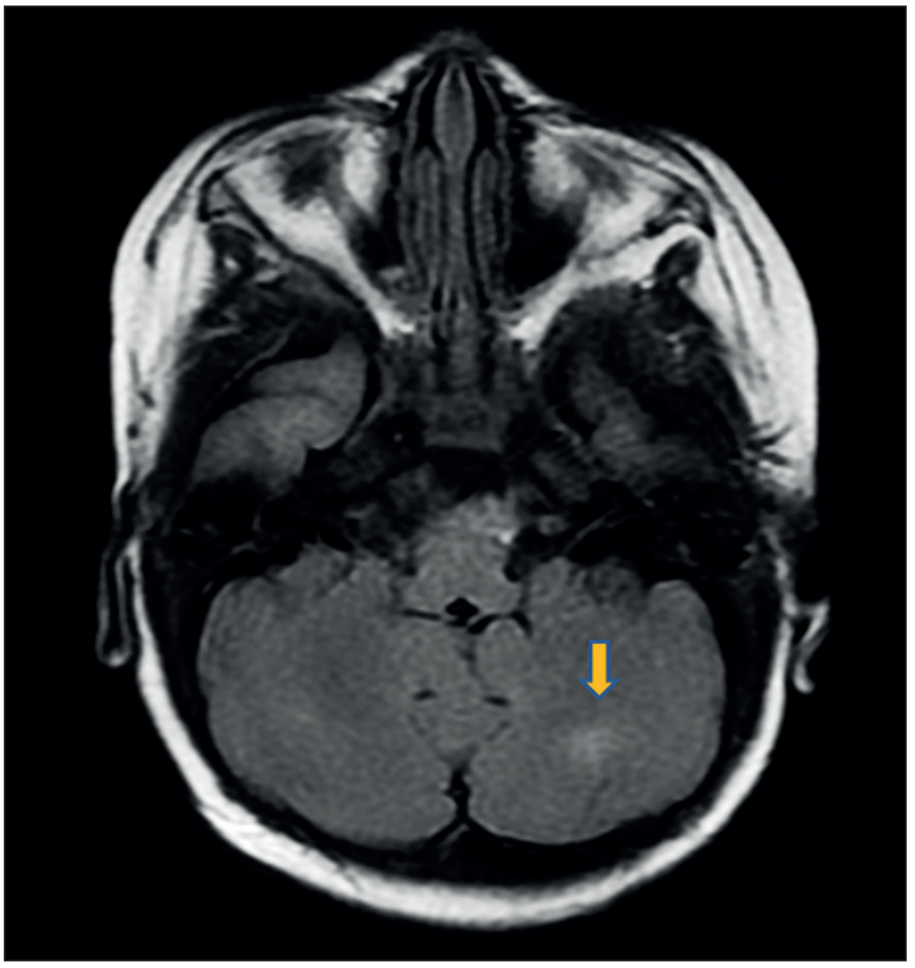

Figura. Imagen de resonancia magnética encefálica que muestra una lesión hiperintensa en T2/FLAIR en relación a la sustancia blanca subcortical cerebelosa izquierda (flecha) compatible con causa inflamatoria/desmielinizante.

cualitativo de conciencia no atribuible a efecto farmacológico residual. El análisis citoquímico del líquido cefaloraquídeo (LCR) mostró glucosa $121 \mathrm{mg} / \mathrm{dL}$; proteínas $119 \mathrm{mg} / \mathrm{dL}$; hematíes $30 / \mathrm{mm}^{3}$; leucocitos 18/ $\mathrm{mm}^{3} ; 100 \%$ mononucleares. Bandas oligoclonales, cultivo corriente y PCR SARS-CoV-2 en LCR resultaron negativos. El electroencefalograma (EEG) evidenció ocasional lentitud intermitente temporal izquierda. Se realizó resonancia nuclear magnética (RNM) de encéfalo y médula total que evidenció foco inflamatorio/ desmielinizante subcortical cerebeloso izquierdo (figura). Se indicó pulso de metilprednisolona $(30 \mathrm{mg} / \mathrm{kg} / \mathrm{d})$ el cual fue efectivo con mejoría en nivel de conciencia y tono de extremidades luego de 3 dosis. EEG de control una semana posterior fue normal, alta a su domicilio al día 21 de hospitalización. La recuperación neurológica fue completa en el control ambulatorio tres meses posterior al alta con RNM de encéfalo y médula normal.

Dentro de las secuelas neurológicas post-infecciosas del COVID-19 están el Síndrome de Guillaín-Barré y ADEM, siendo esta última entidad reportada con una incidencia de $1.3 \%$ en los pacientes menores de 21 años con MIS-C ${ }^{1}$.

En la casuística nacional no se reportaron casos de ADEM, postulándose como uno de los factores la menor magnitud de la respuesta inflamatoria sistémica presente en estos pacientes en relación a los adultos ${ }^{2}$. Por otra parte, un 11\% de los niños con MIS-C presentaron manifestaciones neurológicas inespecíficas como debilidad muscular (29\%) y encefalopatía (11\%) en el contexto de falla multisitémica, todos con una pronta mejoria $^{2}$. En otra serie de casos nacional ${ }^{4}$, un $25 \%$ de los pacientes con MIS-C presentó complicaciones neurológicas, no señalándose casos de ADEM.

Referente al presunto mecanismo fisiopatológico involucrado en el compromiso neurológico en el paciente con MIS-C este se atribuye a la pérdida de la integridad de la barrera hemato-encefálica ocasionada por la existencia de una "tormenta" de citoquinas (característico incremento de los biomarcadores inflamatorios) $)^{5}$.

En el niño con disfunción multiorgánica la presencia de encefalopatía es multifactorial, pero cursa con una progresiva recuperación en relación a la mejoría de la enfermedad de base y la eliminación de factores asociados (tóxico-metabólicos, convulsiones, etc.). De esta manera, al no observarse el progreso esperable, se debe ser proactivo en descartar esta complicación.

La presente comunicación permite destacar que en el curso de MIS-C puede existir una grave complicación como ADEM. Aunque en un inicio el tratamiento inmunomodulador con altas dosis de metilprednisolona y IGIV no varía de forma significativa, es de importancia una precoz intervención pues un tratamiento oportuno tiene resultados clínicos favorables, además de ser relevante el disponer de este antecedente para un adecuado seguimiento. Finalmente, en el niño con MIS-C y encefalopatía con déficit neurológico se debe considerar la eventual existencia de ADEM, entre las posibles complicaciones del sistema nervioso central.

\section{Referencias}

1. LaRovere KL, Riggs BJ, Poussaint TY, et al. Neurologic Involvement in Children and Adolescents Hospitalized in the United States for COVID-19 or Multisystem Inflammatory Syndrome. JAMA Neurol. 2021;78(5):536-47.

2. Sandoval F, Julio K, Méndez G, et al. Neurologic Features Associated With
SARS-CoV-2 Infection in Children: A Case Series Report. J Child Neurol. 2021 Mar 1:883073821989164.

3. McLendon LA, Rao CK, Da Hora CC, Islamovic F, Galan FN. Post-COVID-19 Acute Disseminated Encephalomyelitis in a 17-Month-Old. Pediatrics. 2021;147(6):e2020049678.

4. Yagnam F, Izquierdo G, Villena R, González C, Drago-T M. Síndrome Inflamatorio Multisistémico Pediátrico asociado a COVID-19: Características clínicas y manejo en una Unidad de Paciente Crítico Pediátrico. Andes pediatr. 2021;92(3). DOI: 10.32641/ andespediatr.v92i3.3333.

5. Aghagoli G, Gallo Marin B, Katchur NJ, Chaves-Sell F, Asaad WF, Murphy SA. Neurological Involvement in COVID-19 and Potential Mechanisms: A Review. Neurocrit Care. 2021;34(3):10621071. 